\title{
IN NEED OF MEDIATION: THE RELATION BETWEEN SYNTAX AND INFORMATION STRUCTURE*
}

\author{
GISBERT FANSELOW \\ Universität Potsdam \\ Institut für Linguistik \\ SFB 632 „Informationsstruktur“ \\ Karl-Liebknecht-Straße 24-25 \\ 14476 Golm, Germany \\ fanselow@uni-potsdam.de
}

\begin{abstract}
This paper defends the view that syntax does not directly interact with information structure. Rather, information structure affects prosody, and only the latter has an interface with syntax. We illustrate this point by discussing scrambling, focus preposing, and topicalization. The position entertained here implies that syntax is not very informative when one wants to narrow down the interpretation of terms such as "focus", "topic", etc.
\end{abstract}

Keywords: givenness, scrambling, focus, topic, cartographic approach

\section{Four issues in the interaction of syntax and information structure}

The status of the information expressed by the parts of an utterance relative to the utterance's common ground (Krifka 2008) influences the form of the utterance. This comes out clearly when one considers the prosodic shape of a sentence, in which "given" elements are usually unaccented in languages such as German or English, or when one considers morphological markers such as Japanese wa signaling topicality. One would expect, then, that the "information structure" of a sentence is also mir-

* I would like to thank Caroline Féry, Shin Ishihara, Denisa Lenertová, Stavros Skopeteas, Thomas Weskott, and Malte Zimmermann for discussions that shaped the content of the present paper substantially. The research reported here was partially supported by DFG grant SFB 632/A1 and D2. 
rored in its syntactic makeup, and the rich literature on topics such as scrambling, focus movement, left and right dislocation, and the like, mirrors the widespread (if not unanimous) conviction that syntax matters for the information structure of an utterance, and that an utterance's information structure can influence the choice of its syntactic shape.

This consensus concerning the existence of a relation between syntax and information structure allows for the existence of the multitude of models currently entertained for the precise nature of the interaction between syntax and information structure. Several of the controversial issues are generated more by specifics of the overall grammatical system presupposed in these models than by empirical facts exclusively concerning the expression of information structure.

One example is the issue whether information structure is a separate level of representation, in addition to Phonological Form, Logical Form, and S-structure. as postulated, e.g., by Vallduví (1992), which presupposes a multistratal and representational view of syntax such as the Principles and Parameters Theory (Chomsky 1981). The Principles and Parameters Theory also had an architectural property that influenced the discussion of information structure substantially (see also Horvath 2007): if there is no direct communication between Phonological Form and Logical Form (as Chomsky 1981 assumes), the information that a category is accented (and can thus be the focus or part of the focus) must travel to semantics via syntax, where it will have to be coded by devices such as F-marking. The pertinent features and machinery reflect little more than an attempt to uphold an architectural assumption (PF does not influence LF) in the light of counterevidence (prosody is crucial for interpretation), and can, in principle, be abandoned in models such as (recent) Minimalist Syntax (Chomsky 2005) with a more or less parallel cyclic derivation of form and meaning. After all, syntactic objects are triplets of phonological, syntactic, and semantic features in Minimalist Syntax, so that there is no compelling reason for phonology and semantics needing communicative assistance by syntax (cf. also Büring 2007 in this respect).

This insight leads to what appears to me to be the first of four theoryneutral issues in modeling the syntax-information structure interaction: is it direct or indirect? In a direct model, information structure corresponds to syntactic features (such as focality or givenness) or heads such as Topic or Focus (as in the cartographic approach of Rizzi 1997), and these figure in the syntactic computation. Of course, such direct models 
are the only ones for which it makes sense to ask what light syntax can shed on the definition and application of notions of information structure.

In indirect models, on the other hand, prosody interacts with information structure, and is at the same time relevant for syntactic computations. Thus, XPs may move in order to pick up an accent in certain positions, or they may move in order to allow other XPs to occupy prosodically prominent positions. See Zubizarreta (1998), Szendrői (2001) and Samek-Lodovici (2005) for such approaches. When syntactic objects move and thereby change their own prosodic properties (or the prosodic properties of their neighbours), this movement will affect the information structure potential, given the strong link between prosody and information structure. The result is an indirect interaction between syntax and information structure.

The term licensing is frequently used when one talks about the relation between syntax and information structure, and the attempts to make this notion precise span a second dimension of truly empirical issues in the syntax-information structure interaction. Syntacticians usually prefer to speak of the "triggering" of some process, meaning thereby that the presence of some feature such as " + wh" is responsible for the displacement of a $w h$-phrase to Spec,CP - the movement is an automatic and quasi inevitable consequence of the presence of the feature. When we consider information structure, we often encounter something different: a category that is given, or focused, or topical, can be moved to a certain position, but does not have to be so. The information structure status of an XP may be a necessary condition for movement, but not a sufficient one. In this respect, the impact of information structure on syntax differs substantially from other domains such as operator movement (wh-phrases, quantifiers) or movement to argument positions. In these areas, movement is either obligatory or forbidden, and optionality is the exceptionquite in contrast to what we observe with information structure. This fundamental difference must be reflected in a good syntactic theory.

We could speak of the mere "licensing" of movement in the case of information structure. The idea that movement can be "licensed" can be made precise in at least two different ways. The first possibility is that the syntax "sees" and "works with" the information structure properties licensing the movement. There might, e.g., exist a topic feature that can optionally be present on a head such as Comp, and trigger movement when it is present. The second possibility is that the mechanics of syntax are blind to "licensing" features. Such a situation might hold when 
there is constraint that requires, e.g., that topic must be left-peripheral in a purely linear sense, but does not care about the precise nature and hierarchical properties of the left periphery (see e.g., Pereltsvaig 2004). Different processes with different causal bases such as passivization, adjunction to TP, movement to Spec,CP, etc., might serve this function in a given language. The information structure distinction would thus "exploit" syntactic possibilities intrinsically unrelated to information structure. We will reserve the term licensing for the first possibility in the rest of the paper.

A third issue, perhaps the one closest to the overall topic of this volume, is whether the distinctions of information structure syntacticians typically apply when they talk about licensing (topic, focus, given, contrast) are really helpful in describing the syntax information structure interaction. E.g., these notions are all "backward looking" and ignore the "forward looking perspective" shown to be crucial for pronoun resolution by Centering Theory (Walker et al. 1998). Similarly, it is often claimed that the referents of XPs must be "salient" or constitute "unexpected information" for there to be changes in constituent order. These notions do not fit straightforwardly into models of information structure.

Finally, there is the issue of whether we look at the right pragmatic level when we try to understand free constituent order. A notion such as contrast may apply to relations between propositions in a text, or it may apply to parts of pairs of propositions. When we say that information structure affects word order, we mean the latter pragmatic level, but it does not go without saying that word order variation is not functional at the former level.

In the following sections, I want to shed some light on these issues by looking at word order variation. The evidence we discuss supports the view that syntax and information structure interact indirectly, and more in the sense of exploitation than triggering.

\section{Word order variation in the innermost clausal layer: TP}

Within the innermost clausal layer TP, the difference between [+given] and [- given] information seems to be the major factor behind constituent order variation, and it has already been noted by Mathesius (1975); Tomlin (1995), among others, that passivization and simple reordering, i.e., scrambling, are the primary means for responding to that distinction. 
The choice of an OSV structure seems mandatory under certain pragmatic conditions in some languages (Czech: Veselovská 1995; Kučerová 2007), but optional in others (German: Lenerz 1977; Turkish: Temürcü 2001). Scrambling would thus be triggered in a strict sense in Czech, but we found it difficult to pin down the obligatoriness of scrambling experimentally (see Skopeteas-Fanselow 2008a). Such difficulties notwithstanding, the differences in the likelihood of the choice of a marked word order in different languages must find an explanation. The set of plausible accounts is narrowed down by the observation that the givennessrelated laws, be they optional or not, also apply to pairs of XPs that are not scrambled relative to each other. Thus, given $>$ new holds of pairs of adjuncts, too (see Lenerz 1977), although adjuncts arguably do not scramble (Haider-Rosengren 2003). Likewise, given $>$ new is respected within DP-coordinations (Kučerová 2007), and there is no coordinationinternal scrambling. Passivization can be used to establish given $>$ new order even in languages such as German (see Skopeteas-Fanselow 2008a) in which the passive does not involve movement (Lenerz 1977). The generalization given $>$ new thus does not stem from a feature $g$ borne by a phrase that is attracted by a head in the context of $g$-agreement.

Zubizarreta (1998) and Samek-Lodovici (2005) argue that the position of focus is determined prosodically in the Romance languages: the intonational center that must fall together with the focus must be rightmost in the clause. Such a constraint on the positioning of focus/prosodic prominence requires the placement of unaccented/given phrases in the left part of the sentence. Coming back to Czech, Veselovská (1995) observes that the word order properties of Czech are much like those of Catalan, and indeed, the intonation center of Czech is right-peripheral (Chaminikolasová 1995). It thus comes as no surprise that the apparent obligatoriness of marked word order in Czech (in the relevant context) has been (partially) linked to the idea that unaccented XPs must be placed into the left part (above vP) of the sentence (Biskup 2006).

One argument favoring a prosody-driven account of scrambling lies in the fact that languages with a higher degree of optionality of scrambling (such as German, Georgian, and Turkish) are also prosodically more flexible than Czech, Catalan or Italian. The rigidity of the prosodic laws in the latter languages cannot be interpreted as a side-effect of obligatory movement of given phrases, because this rigidity in the placement of the intonational center in Czech and Italian holds for structure not 
containing given material at all (i.e., wide focus utterances), too. This establishes that prosody is the cause, and scrambling the consequence.

Various theories of accent placement in German (Cinque 1993; Samek-Lodovici 2006; Féry-Kügler to appear, among others) imply that the "main" accent should be as far to the right as possible. The constraint is violable in the sense that it does not rule out the realization of basegenerated "normal" order. However, it constrains scrambling because an application of movement within TP must not make the structure worse with respect to accent placement.

In the domain of scrambling, we thus only see an indirect interaction of information structure and syntax. What syntax responds to is the need of (or the preference for) placing prosodic prominence into a specific position. ${ }^{1}$

One issue remains: The mechanics of scrambling have to be identified. Syntacticians often postulate a scrambling ("[+scr]", " $\Sigma$ ") feature (Müller 1998; Grewendorf-Sabel 1999). This feature is introduced in the hope (often explicitly formulated) that a pragmatic interpretation for the feature can be found at some future date, but if the prosodic model is correct, the hope is not warranted. ${ }^{2}$ Haider and Rosengren (2003) concur with our view, on the basis of additional arguments: they show that none of the proposals for spelling out the interpretation of the scrambling feature works. Scrambling features are thus nothing but a technical device for not admitting that scrambling is syntactically untriggered and optional. One may even doubt whether free argument order is due to movement. There is ample discussion of this issue in the literature

${ }^{1}$ Frey (2004a) has argued for a position for sentence topics above TP, to the left of sentence adverbials, cf. also Haftka (1995). According to Frey, the notion relevant for topic placement is "aboutness", as proposed by Reinhart (1981; 1995). The need for this position is not beyond doubt, however. German word order is sometimes incompatible with such a position (see Fanselow 2003; 2006). Nearly all observations concerning topic placement in Frey (2004a) involve the positioning of topics relative to sentence adverbs. Engels (2004) shows, however, that the position of topics relative to sentence adverbs is better explained if the latter are analyzed as focus (accent) sensitive operators, cf. also Fanselow (2006).

${ }^{2}$ A further difficulty for the view that scrambling is triggered by a pragmatically interpretable feature of the scrambled phrase arises if scrambling also figures in the derivation of remnant movement (Müller 1998) and clause union constructions (Wurmbrand 2001). The scrambling operations required for these processes do not change linear order, and are not subject to any pragmatic constraints. This corroborates the view that the pragmatic constraints are not involved in the syntactic mechanics of scrambling.

Acta Linguistica Hungarica 55, 2008 
(Fanselow 2001; Haider-Rosengren 2003) that we do not want to summarize. Rather, we wish to point to a consequence of the prosodic view of scrambling that favors base-generation. Prosodically driven scrambling would have to be altruistic movement: what matters for the movement of $\mathrm{X}$ across $\mathrm{Y}$ is not a property of $\mathrm{X}$ but of $\mathrm{Y}$. Therefore, there should be no restriction on the choice of $\mathrm{X}$. It thus comes as a surprise that parts of idioms do not undergo scrambling in German (although they do in Japanese, see Miyagawa 1997), as illustrated in (1c) with the idiom das Zeitliche segnen. To the extent that idioms must be merged as a unit, the absence of idiom scrambling would be a consequence of a base generation account of free word order, however.

(1) (a) Hat Fritz das Zeitliche gesegnet?

has Fritz the temporal blessed

'Has Fritz died?'

(b) Fest steht, dass nur Peter das Zeitliche gesegnet hat. firm stands that only Peter the temporal blessed has 'It is established that only Peter has died.'

(c) ?? Fest steht, dass das Zeitliche nur Peter gesegnet hat.

\section{Leftward focus placement}

The leftward movement of a focus in the clausal layer above TP may appear to be a more promising candidate for a direct interaction of syntax and information structure than scrambling. Brody (1990) argues for a special functional projection of a focus head above TP in Hungarian. Hungarian also seems to show that such focus movement can be obligatory. In many languages, focus movement was furthermore argued to be restricted to certain subtypes of focus, see Drubig (2003) for a summary.

Let us first briefly consider focus typology in its relation to movement. É. Kiss (2008) summarizes the widespread assumption that focus movement is confined to and obligatory for exhaustive foci in Hungarian. Wedgwood (2003) argues that exhaustiveness and focus position are linked only by pragmatic implication in Hungarian (such that syntax would not have to operate with a feature "exhaustive"). In the present context, it is, however, more important that Horvath (2007) showed that the exhaustively interpreted XPs moving to the left in Hungarian need not be foci. In other words, the obligatory movement of XPs to the preverbal position in the Hungarian $\mathrm{CP}$ is linked to/triggered by a semantic 
feature (exhaustivity), and not by focus. We get the impression of focus movement because being in focus and being interpreted exhaustively are intimately connected (but not identical) notions.

That syntactic movement should be intimately tied to a semantic property such as exhaustive interpretation is not predicted by many syntactic models. Regardless of how this difficulty can be overcome, Horvath's analysis shows that interpretation influences word order, as it does in the case of quantifier movement to the left that must be assumed for Hungarian on independent grounds. The interpretive influence applies at the semantic level, however, and not at the level of information structure.

A semantic rather than a pragmatic effect may also contribute to the close to obligatory nature of moving given material in Czech. There is a tendency (Ivona Kučerová, p.c.) that scrambling is less optional in languages lacking a determiner system. In such languages, specificity and definiteness are not expressed morphologically, but in terms of linear position. Biskup (2006) argues that the pertinent semantic features play a role for Czech scrambling.

Summing up, the strongest case for obligatory focus fronting must probably be reinterpreted as an obligatory movement of an exhaustively quantified XP, i.e., it is due to semantic rather than pragmatic triggering.

That the fronting of foci is restricted to contrastive foci has been claimed for several languages such as Italian (Rizzi 1997), Plains Cree (Mühlbauer 2003), and German (Frey 2004b). Frey (2004b) has brought the notion of "contrast" into the discussion of German word order. According to him, focus fronting and long topic movement are only possible when there is an (additional, implicit) contrast involved. Thus, he considers (2c) an odd answer to (2a) in a normal context.

(2) (a) Wo liegt Köln?

where lies Cologne

'Where is Cologne situated?'

(b) Köln liegt am Rhein.

Cologne lies on-the Rhine

'Cologne is on the river Rhine.'

(c) Am Rhein liegt Köln.

The effect is subtle (so that many speakers do not perceive it) and may involve no more than the existence of a contextually salient set of alternatives from which the answer selects in the case of (2c). We can front the focus if it picks an answer from that set.

Acta Linguistica Hungarica 55, 2008 
However, an XP can move to the left periphery in German even when contextually salient contrast sets cannot be assumed. Contexts normally do not specify alternative sets (as required for a contrastive analysis) for names of new students, yet $(3 \mathrm{~b}-\mathrm{c})$ are perfect answers to (3a). (4) illustrates the same point: a noun phrase referring to a quantity can be fronted even though it is not likely that contexts establish salient alternative sets here.

(3) (a) Wie heisst die neue Studentin?

'What is the name of the new student?'

(b) Anna Lesinski heisst die Gute

A. L. is-called the good

'The good girl is called Anna Lesinski.'

(c) Anna Lesinski denk ich dass sie heisst

A. L. think I that she is-called

'I think she is called Anna Lesinski.'

(4) (a) Wieviel kosten der Roman von Anna und die Gedichte von Peter?

'How much do the novel by Anna and the poems by Peter cost?'

(b) 40 Euro kosten die beiden Bücher zusammen.

40 euro cost the both books together

'The two books cost 40 Euro together.'

"Contrast" is thus not necessary for focus fronting in German. Brunetti (2004) draws the same conclusion for Italian: contrastivity does not play a role for the positioning of the focus. See also Samek-Lodovici (2005) for a similar view.

There is a further observation that makes the postulation of a syntactically relevant feature "contrastive" doubtful. Dahlstrom (2003) notes for Meskwaki (Fox) that focus fronting does not only apply in contrastive contexts, but also when the content of the utterance is somewhat unexpected. This is reminiscent of Zimmermann's (this volume) remark that untypical objects appear more frequently in the left periphery of a clause than typical ones in Hausa. The same appears to hold for Georgian (see Skopeteas-Fanselow 2008b).

It is difficult to make the notion of the 'typicality' of an event precise. To the extent that it matters for focus fronting, it obviously adds a dimension that does not belong to information structure in a standard sense, viz. it refers to a ranking within the set of alternatives figuring in the definition of focus. Contrast, correction, and low typicality cluster 
together, in that they imply that the whole proposition has a low predictability in the context of the utterance. We may draw the (obvious) conclusion that the choice of a marked structure (fronted focus) is more likely when the speaker is interested in getting increased attention from the listener. We may speculate that the function of preposing does not lie in the expression of focus, but in increasing the listener's attention by the choice of an unexpected syntactic construction.

The view that the function of fronting is not the marking of focus but the attempt of increasing the listener's attention is supported by a further property of so-called focus fronting. If the pragmatic property of "focality" is the factor responsible for fronting, we would expect that the category that moves is identical with the focus of the utterance, or slightly larger, as determined by the laws of syntactic pied piping. However, when we consider focus fronting constructions in a variety of languages, we observe that the category that undergoes movement may be smaller than the actual focus (5b), or larger than the focus even without a grammatical need for pied-piping (6c), and sometimes it may even happen to coincide with the focus $(6 \mathrm{~b})$.

(5) (a) Was hast du am Sonntag gemacht? 'What did you do last Sunday?'

(b) Einen Schrank hab ich lackiert. a cupboard have I painted 'I painted a cupboard.'

(6) (a) Was hast du gekauft? 'What have you bought?'

(b) Ein BUCH hab' ich mir gekauft. a book have I myself bought

(c) [vp Ein BUCH gekauft] hab ich mir. 'I bought a book.'

Data such as (5) have been frequently noted for German (see, e.g., Jacobs 1991; Büring 1997; Krifka 1994), for Hungarian (Szabolcsi 1981; Kenesei 1998), and they occur in the Slavic languages, in Dutch, Greek, Italian, Finnish, and further languages (see Fanselow-Lenertová 2008), but their import for an understanding of the nature of "focus movement" has not been fully appreciated. Data such as (6c) (or, rather, their Hungarian counterparts) have been first discussed by Horvath (2007).

Horvath points out that displacement in focus constellations must have the typical properties of movement, in particular, it should respect 
the laws for pied-piping. We observe, however, that an XP containing the focus of an utterance can be fronted in focus constructions even when the position the focus expression occupies in XP does not license the pied-piping of XP otherwise. For instance, an expression must be the specifier or the head of an XP for triggering the pied-piping of XP in Hungarian, but XP can move to the "focus position" even if the "real" focus occupies a complement position in XP. Horvath concludes that the movement of such XPs cannot be interpreted as being triggered by focus, and that the position targeted by such XPs cannot be a focus position. This renders the analysis of the Hungarian preverbal position as a focus position unlikely in general.

In $(5 \mathrm{~b})$, the focus has not been moved as a whole. The position for a focus can also be targeted by only a part of the focus in quite a number of languages. A detailed discussion of this construction can be found in Fanselow-Lenertová (2008). They show that, in general, the fronted subpart of the focus has no information structure property of its own that might have licensed the preposing.

The category that moves in such constellations must contain the leftmost accented part of the focus in Czech, German, and Polish. This constraint may suggest that accentuation is the property crucial for movement (as proposed in Fanselow 2004), but this would not explain why the same phenomena occur in languages such as Hausa (Hartmann-Zimmermann 2007), Trinidadian English and Haitian (Cozier 2006) in which the focus is not or need not be prosodically marked.

Data such as (5) and (6) suggest that it does not matter what is preposed in a focus construction - it can be the focus, or a category smaller or larger than the focus. ${ }^{3}$ What matters is merely the choice of a marked construction, that can increase the listener's attention. If correct, this means that what was analyzed as focus fronting is not licensed by "focus". The licensing rather lies at a different pragmatic level.

Further support for this view comes from the results of an acceptability rating experiment carried out in collaboration with Reinhold Kliegl and Thomas Weskott. We found that syntactically unmarked SVO sen-

${ }^{3}$ Still, one would like to know what determines the choice among these options. In Polish, partial fronting is more colloquial than complete fronting (Pawel Rutkowsky, p.c.), while the use of partial fronting signals annoyance in SerboCroatian (Damir Ćavar and Tijana Asič, p.c.). It is difficult to see how such factors could figure in a syntactic description of the construction. Such usage difference are probably handled best by rules of style. 
tences such as (7a) are less acceptable in German than syntactically marked OVS sentences $(7 \mathrm{~b})$ when they restrict the validity of a preceding general statement (as in mini-texts such as He cleaned the car completely. He forgot the outside mirror). The strong acceptability advantage of the object initial sentence disappears, however, if a marker of contrast (aber 'but, however') is inserted into a subject initial sentence (7c). In other words, in such texts, the failure of signaling the contrast between two sentences leads to inacceptability, but it does not matter if contrast is signaled by a sentence particle, or by the use of marked word order.

(7) (a) Er hat den Aussenspiegel vergessen

'He has the outside mirror forgotten.'

(b) Den Aussenspiegel hat er vergessen.

(c) Er hat aber den Aussenspiegel vergessen.

he has however the outside mirror forgotten

'(However,) he forgot the outside mirror.'

The phenomenon of subpart of focus fronting on the one hand, and the relevance of semantic concepts such as exhaustivity rather than pragmatic ones suggest that classifying certain leftward movement constructions as "focus movement" is a misconception. What has been analyzed as focus movement is triggered by a semantic rather than pragmatic property, or is licensed by a pragmatic relation between sentences different from "information structure".

\section{Topic placement}

One important claim of the cartographic approach to information structure (Rizzi 1997) lies in the idea that topics and foci stand in a crosslinguistically stable hierarchical relation relative to each other. In the version advocated by Benincà (2001) topics c-command the focus. ${ }^{4}$ This holds true in a wide variety of languages such as Hungarian, Kinande (Schneider-Zioga 2007), Plains Cree (Mühlbauer 2003) and Warlpiri (Legate 2002), in which topics precede foci. Malagasy shows that hierarchy rather than linear order is important: Topics and foci occur on different

${ }^{4}$ This means that the second position for "topics" below the focus was eliminated. Note that this second position behaves differently from the upper topic position. For example, it cannot bind a clitic. See Benincà (2001) for further arguments. 
edges of the clause in this language, such that foci precede topics, but the latter still c-command the former (Pearson 2005).

The cartographic approach is a good description of the fact that topics c-command foci, but does not really explain it. After all, the generalization only follows from the hierarchical relation between the TOPIC and the FOCUS head, which is itself stipulated. Rizzi (1997) identifies a number of differences between topic and focus constructions: the former involve clitic-left dislocation (CLLD), while the latter are XP-trace constellations. One also finds topics coindexed with empty operators (Pearson 2005). The hierarchical relation between topics and foci can, in principle, be interpreted in terms of the syntactic differences just mentioned, if "focus" fronting targets the specifier of a CP, while topic left dislocation involves a phrase adjoined to the maximal C-projection. The "focus" is then always lower than the topic, because Spec,CP is structurally lower than an adjunct to $\mathrm{CP}$.

For the story to become complete, we need to specify why foci move to Spec,C (rather than adjoining to $\mathrm{CP}$ ), and why topics adjoin to $\mathrm{CP}$ (rather than moving to Spec,C). For intonation languages, the answer can be sought in the prosody-syntax interface. Suppose that structural (noncontrastive) accents are assigned to specific positions included in $\mathrm{CP}$, in a language particular fashion: the leftmost element in $\mathrm{CP}$ is accented in Hungarian (see Szendröi 2001), accents can go the most deeply embedded category in some languages (as suggested by Cinque 1993 for German), or they might be determined relative to the spellout domains VP and TP of phases (Kratzer-Selkirk 2007). If foci need structural accents, it is then clear why they cannot be merged as adjuncts to CP.

Topics are different. They need no structural accents, because they are not part of the focus, so they can be merged in any position, including the adjunct position of CP. If topics need to be set off prosodically from the rest of the clause, with an intonation phrase of their own, this prosodic requirement narrows down the number of positions where topics may occur in. In particular, if the minimal CP itself cannot be broken up into two or more intonation phrases, then topics must be adjoined to CP.

Baker $(1988 ; 1996)$ has shown that unmarked Mohawk clauses have the structure of clitic left dislocation constructions, without sharing the pragmatics of Romance CLLD constructions, as Baker (2001) points out. All overt NPs (except for wh-phrases) are left-dislocated in Mohawk, but they are not necessarily topics. Baker concludes that there can be no universal link between positions and sentence types on the one hand, 
and information structure on the other. He argues that marked syntactic structures (such as CLLD constructions) come with a marked pragmatics (topic interpretation) only when they compete with simpler syntactic structures. Mohawk XPs cannot surface in argument positions, so they have no marked interpretation when left-dislocated.

Likewise, we have observed in a language production experiment that the simple givenness of an XP licenses its movement to topic position in Hungarian (Skopeteas-Fanselow 2008a), quite in contrast to the other 12 languages we have tested. If the postverbal field of Hungarian can contain only backgrounded material, Baker's (2001) idea helps to understand why the conditions for filling the topic position are relaxed in Hungarian: the "unmarked" postverbal slot is unavailable.

\section{Conclusions}

The present overview of the syntax-information structure relation has left open more issues than it has actually addressed. We have not commented on cleft formation, and we have been silent on the various subclasses of topics, which seem to have a stable ordering relative to each other. And our emphasis was on the analysis of German and structurally similar languages, in which prosody responds to information structure in a clear way.

Within the limits of these provisos, we have shown that syntax does not have a direct interface with information structure. It responds to distinctions of information structure only when these translate into prosodic categories, or correlate with semantic properties. This finding is in line with the basic architecture of grammar entertained in the Minimalist Program (the same was true of the Principles and Parameters Theory). After all, syntax interacts with the phonological and the conceptual-intentional (CI) system only, and if the CI system is understood in a narrow sense, it is distinct from the "discourse storage" or the representation of the common ground.

\section{References}

Baker, Mark 1988. Incorporation: A theory of grammatical function changing. University of Chicago Press, Chicago.

Baker, Mark 1996. The polysynthesis parameter. Oxford University Press, New York. 
Baker, Mark 2001. The natures of nonconfigurationality. In: Mark Baltin-Chris Collins (eds): The handbook of contemporary syntactic theory, 407-38. Blackwell, Malden MA \& Oxford.

Benincà, Paolo 2001. The position of topic and focus in the left periphery. In: Guglielmo Cinque - Giampaolo Salvi (eds): Current studies in Italian syntax: Essays offered to Lorenzo Renzi, 39-64. Elsevier, Amsterdam.

Biskup, Petr 2006. Scrambling in Czech: Syntax, semantics, and information structure. In: UBC Occasional Papers in Linguistics 1:1-15.

Brody, Michael 1990. Some remarks on the focus field in Hungarian. In: UCL Working Papers in Linguistics $2: 201-26$.

Brunetti, Lisa 2004. A unification of focus. Unipress, Padova.

Büring, Daniel 1997. The meaning of topic and focus - The 59th Street Bridge accent. Routledge, London.

Büring, Daniel 2007. Semantics, intonation and information structure. In: Gillian Ramchand - Charles Reiss (eds): The Oxford handbook of linguistic interface, 445-73. Oxford University Press, Oxford.

Chaminikolasová, Jana 1995. Intonation center in English and Czech sentences. In: Brno Studies in English $21: 9-15$.

Chomsky, Noam 1981. Lectures on government and binding. Foris, Dordrecht.

Chomsky, Noam 2005. On phases. Manuscript. MIT.

Cinque, Guglielmo 1993. A null theory of phrase and compound stress. In: Linguistic Inquiry $24: 239-97$.

Cozier, Franz 2006. The relationship between focusing and clefting in Trinidadian Dialectal English. Manuscript. MIT.

Dahlstrom, Amy 2003. Focus constructions in Meskwaki (Fox). In: Miriam ButtTracy Holloway King (eds): Proceedings of the LFG03 Conference. CSLI, Stanford.

Drubig, Hans Bernhard 2003. Toward a typology of focus and focus constructions. In: Linguistics $41: 1-50$.

É. Kiss, Katalin 2008. Topic and focus: Two structural positions associated with logical functions in the left periphery of the Hungarian sentence. In: Acta Linguistica Hungarica 55 : 287-96.

Engels, Eva 2004. Adverb placement. An Optimality Theoretic approach. Doctoral dissertation, Potsdam.

Fanselow, Gisbert 2001. Features, theta-roles, and free constituent order. In: Linguistic Inquiry $32: 405-37$.

Fanselow, Gisbert 2003. Free constituent order. A minimalist interface account. In: Folia Linguistica $37: 191-231$.

Fanselow, Gisbert 2004. Cyclic phonology-syntax interaction: Movement to first position in German. In: Shin Ishihara - Michaela Schmitz (eds): Interdisciplinary studies on information structure (Working Papers of the SFB 632, 1), 1-42. University of Potsdam, Potsdam.

Fanselow, Gisbert 2006. On pure syntax. In: Patrick Brandt-Eric Fuss (eds): Form, structure and grammar, 137-57. Akademie Verlag, Berlin. 
Fanselow, Gisbert-Denisa Lenertová 2008. Left peripheral focus. Mismatches between syntax and information structure. Manuscript. University of Potsdam.

Féry, Caroline-Frank Kügler to appear. Pitch accent scaling on given, new and focused constituents in German. In: Journal of Phonetics.

Frey, Werner 2004a. A medial topic position for German. In: Linguistische Berichte $198: 153-90$.

Frey, Werner 2004b. The grammar-pragmatics interface and the German prefield. In: Sprache und Pragmatik 52:1-39.

Grewendorf, Günther-Joachim Sabel 1999. Scrambling in German and Japanese: Adjunction versus multiple specifiers. In: Natural Language and Linguistic Theory $17: 1-65$.

Haftka, Brigitte 1995. Syntactic positions for topic and contrastive focus in the German middlefield. In: Inga Kohlhof - Susanne Winkler - Hana Bernhard Drubig (eds): Göttingen Focus Workshop. Arbeitspapiere des SFB 340, Bericht Nr. 69, 137-57. University of Tübingen, Tübingen.

Haider, Hubert - Inger Rosengren 2003. Scrambling: Nontriggered chain formation in OV languages. In: Journal of Germanic Linguistics 15 : 203-67.

Hartmann, Katharina - Malte Zimmermann 2007. In place - out of place: Focus in Hausa. In: Kerstin Schwabe-Susanne Winkler (eds): On information structure, meaning and form: Generalizatons across languages, 365-403. John Benjamins, Amsterdam \& Philadelphia.

Horvath, Julia 2007. Separating focus movement from focus. In: Simin Karimi-Vida Samiian - Wendy K. Wilkins (eds): Phrasal and clausal architecture: Syntactic derivation and interpretation, 108-45. John Benjamins, Amsterdam \& Philadelphia.

Jacobs, Joachim 1991. Focus ambiguities. In: Journal of Semantics $8: 1-36$.

Kenesei, István 1998. Adjuncts and arguments in VP-focus in Hungarian. In: Acta Linguistica Hungarica $45: 61-88$.

Kratzer, Angelika - Elisabeth O. Selkirk 2007. Default phrase stress, prosodic phrasing and the spellout edge: The case of verbs. In: Linguistic Review $24: 93-135$.

Krifka, Manfred 1994. Focus and operator scope in German. In: Peter Bosch-Robert van der Sandt (eds): Proceedings of the Conference on Focus and Natural Language Processing, Volume 1: Intonation and Syntax, 133-52. ILL, Heidelberg.

Krifka, Manfred 2008. Basic notions of information structure. In: Acta Linguistica Hungarica 55 : 243-76.

Kučerová, Ivona 2007. The syntax of givenness. Doctoral dissertation, MIT.

Legate, Julie 2002. Warlpiri: Theoretical implications. Doctoral dissertation, MIT.

Lenerz, Jürgen 1977. Zur Abfolge nominaler Satzglieder im Deutschen. Narr, Tübingen.

Mathesius, Vilém 1975. A functional analysis of present day English on a general linguistic basis. Mouton, The Hague \& Paris.

Miyagawa, Shigeru 1997. Against optional scrambling. In: Linguistic Inquiry 28:1-25.

Mühlbauer, Jeff 2003. Word-order and the interpretation of nominals in Plains Cree. Manuscript. UBC. 
Müller, Gereon 1998. Incomplete category fronting. Dordrecht, Kluwer.

Pearson, Matthew 2005. The Malagasy subject/topic as an $\mathrm{A}^{\prime}$-element. In: Natural Language and Linguistic Theory $23: 381-457$.

Pereltsvaig, Asya 2004. Topic and focus as linear notions: Evidence from Italian and Russian. In: Lingua $114: 325-44$.

Reinhart, Tanya 1981. Pragmatics and linguistics. An analysis of sentence topics. In: Philosophica $27: 53-94$.

Reinhart, Tanya 1995. Interface strategies (OTS Working Papers in Theoretical Linguistics). OTS, Utrecht.

Rizzi, Luigi 1997. The fine structure of the left periphery. In: Liliane Haegeman (ed.): Elements of grammar, 281-337. Kluwer, Dordrecht.

Samek-Lodovici, Vieri 2005. Prosody-syntax interaction in the expression of focus. In: Natural Language and Linguistic Theory $25: 403-46$.

Samek-Lodovici, Vieri 2006. When right dislocation meets the left-periphery: A unified analysis of Italian non-final focus. In: Lingua 116:836-73.

Schneider-Zioga, Patricia 2007. Anti-agreement, anti-locality and minimality. In: Natural Language and Linguistic Theory $25: 403-46$.

Skopeteas, Stavros - Gisbert Fanselow 2008a. Effects of givenness and constraints on free word order. Manuscript. University of Potsdam.

Skopeteas, Stavros - Gisbert Fanselow 2008b. Focus in Georgian and the expression of contrast. Manuscript. University of Potsdam.

Szabolcsi, Anna 1981. The semantics of topic-focus articulation. In: Jeroen Groenendijk - Theo Janssen - Martin Stokhof (eds): Formal methods in the study of language, 513-41. Matematisch Centrum, Amsterdam.

Szendrői, Kriszta 2001. Focus and the syntax-phonology interface. Doctoral dissertation, University College London.

Temürcü, Ceyhan 2001. Word order variations in Turkish: Evidence from binding and scope. Doctoral dissertation, Middle East Technical University, Ankara.

Tomlin, Russel 1995. Focal attention, voice, and word order: An experimental, crosslinguistic study. In: Pamela Downing - Michael Noonan (eds): Word order in discourse, 517-54. John Benjamins, Amsterdam \& Philadelphia.

Vallduví, Enric 1992. The information component. Doctoral dissertation, University of Pennsylvania.

Veselovská, Ludmila 1995. Phrasal movement and X-morphology: Word order parallels in Czech and English nominal and verbal projections. Doctoral dissertation, Palacky University, Olomouc.

Walker, Marilyn - Aravind K. Joshi - Ellen Prince 1998. Centering theory in the discourse. Oxford University Press, Oxford.

Wedgwood, Dan 2003. Predication and information structure. A dynamic account of Hungarian pre-verbal syntax. Doctoral dissertation, University of Edinburgh.

Wurmbrand, Susi 2001. Infinitives, restructuring, and clause structure. Mouton de Gruyter, Berlin \& New York.

Zubizarreta, Maria-Luisa 1998. Prosody, focus, and word order. MIT Press, Cambridge MA. 